\title{
Modernização, sanitarismo e cotidiano urbano: o processo de implantação do sistema de água encanada em Jacobina (1955-1963)
}

Edson Silva*

edisomsilva@gmail.com

\begin{abstract}
Resumo
Na década de 1950, na cidade de Jacobina, interior da Bahia, irrompeu um processo de modernização dos espaços urbanos, sendo edificada uma série de obras na cidade, como a pavimentação das ruas centrais e abertura de uma larga avenida, a construção do serviço de esgoto e água encanada, a organização do serviço de limpeza urbana e a ampliação da rede de energia elétrica. O objetivo do presente artigo é analisar a implantação do sistema de água encanada na cidade neste contexto. Ao longo do texto, abordamos as motivações que mobilizavam representantes políticos locais, jornalistas e médicos na instalação do serviço de água encanada na cidade naquele momento. O texto explora as seguintes questões: Qual a imagem de cidade almejava com as obras? Quais implicações sociais o citado equipamento moderno provocava no cotidiano urbano? Como se deu o processo de instalação do serviço de água encanada em Jacobina, naquele contexto? No sentido de examinar a implantação do equipamento de modernização da cidade, para além da leitura da bibliografia concernente à temática da pesquisa, foram consultadas fontes primárias como periódicos, Código de Posturas, ofícios da administração municipal, Atas da Câmara de Vereadores, leis municipais, textos memorialísticos e fotografias.
\end{abstract}

\section{Palavras-chave}

modernização; sanitarismo; água encanada; Jacobina-BA

Modernization, sanitation and urban everyday life: the process of implantation of the piped water system in Jacobina (1955-1963)

\begin{abstract}
In the 1950s, in the city of Jacobina, in the interior of Bahia, a process of modernization of urban spaces broke out. A series of works were built in the city, such as the paving of the central streets and the opening of a wide avenue. Sewage and piped water, the organization of the urban cleaning service and the expansion of the electric power network. The purpose of this article is to analyze the implementation of the city 's piped water system in this context. Throughout the text, we discussed the motivations that mobilized local political representatives, journalists and physicians to install the city's piped water service at that time. The text explores the following questions: What image of the city did you long for with works? What social implications did the aforementioned modern equipment provoke in everyday urban life? How was the process of installing the piped water service in Jacobina in that context? In order to examine the implantation of the modernization equipment of the city, in addition to reading the bibliography concerning the research theme, primary sources such as periodicals, Code of Postures, municipal administration offices, Minutes of the City Council, municipal laws, memorialistic texts and photographs.
\end{abstract}

\section{Keywords}

modernization; sanitation; water pipes; Jacobina-BA 


\section{Introdução}

No decorrer da década de 1950, a cidade de Jacobina, localizada no interior do estado da Bahia, passou por um processo de modernização do tecido urbano. A partir de 1955, a cidade recebeu um conjunto de transformações urbanísticas, promovidas pela administração municipal em parceria com órgãos federais. Para a imprensa da época, a Jacobina dos anos 50 ganhava ares de "civilidade", "progresso" e vida moderna. O discurso do jornal Vanguarda, espaço de produção discursiva na cidade, anunciava nas suas páginas que havia passado o tempo do "marasmo", da "decadência" e da "estagnação", e emergia em Jacobina um novo tempo: do "desenvolvimento", do "progresso" e da "civilização".

A materialização dessa concepção de cidade e vida urbana, anunciada nas páginas do periódico Vanguarda, implicava a transformação do espaço urbano e a instalação de equipamentos técnicos modernos, o que caracterizava um processo de modernização urbana. O conceito de modernização aqui deve ser entendido enquanto o conjunto de inovações urbanísticas promovidas pela gestão municipal e pelo governo federal, a exemplo das obras de pavimentação das ruas, da abertura de avenidas, da construção do serviço de esgoto e água encanada, da ampliação da rede de energia elétrica.

Entretanto, ressalta-se que para pensar a modernização urbana nas cidades brasileiras não devemos tomar como referência a vida urbana das capitais europeias do século XIX ou XX, caracterizadas pelo ritmo de vida intenso, com a presença de multidões, a pressa e a agitação. Nesse sentido, concordamos com Gervácio Batista Aranha quando chamou atenção para o citado aspecto. Como argumenta o autor, há limites físicos das cidades, que é necessário levarmos em consideração para examinar os processos de modernização e as incorporações dos equipamentos urbanos modernos nas pequenas e médias cidades (ARANHA, 2005, p.79132).

O sociólogo alemão George Simmel, no início do século XX, ao estudar o tipo de individualidade emergente com o crescimento das cidades na modernidade, considerou que o sujeito numa metrópole sofre uma aguçada excitação dos sentidos (aceleração dos estímulos nervosos), gerada pelo ritmo frenético das ruas. Assim escreveu Simmel no consagrado texto " $A$ metrópole e a vida mental":

A metrópole extrai do homem, enquanto criatura que procede a discriminações, uma quantidade de consciência diferente da que a vida rural extrai. Nesta, o ritmo da vida e do conjunto sensorial de imagens mentais flui mais lentamente, de modo mais habitual e mais uniforme. $E$ precisamente nesta conexão que o caráter sofisticado da vida psíquica metropolitana se torna compreensivel - enquanto oposição à vida de pequena cidade, que descansa mais sobre relacionamentos profundamente sentidos $e$ emocionais. (SIMMEL, 1979. p.12).

Simmel caracterizava que a vida urbana nas grandes cidades era marcada pela velocidade e a multiplicidade de relações. Em oposição, estava o ritmo lento das cidades pequenas ou da vida rural, onde as relações se davam de forma mais "habitual e uniforme"; os vínculos sociais entre os sujeitos, de modo mais sentimental e íntimo. Assim, podemos imaginar Jacobina em meados dos anos 1950 e início dos anos 1960, marcada por um ritmo lento, uma cidade em que quase todos se conheciam pelo menos de vista, dos olhares entrecruzados do dia a dia; com as pessoas a conversar nas ruas e calçadas das portas de suas casas; comerciantes que distinguiam seus fregueses pelo contato diário. Uma cidade pequena e provinciana do sertão baiano.

De acordo com a Enciclopédia dos Municípios Brasileiros, publicada em 1958 pelo Instituto Brasileiro de Geografia e Estatística (IBGE), com dados referentes ao Censo Demográfico de 1950, o município de Jacobina tinha uma população de 61.681 habitantes. Em comparação com outros municípios baianos Jacobina era o $11^{\circ}$ mais populoso do estado. Sendo que $83,50 \%$ da população do município estava localizada na área rural. A população urbana da sede do município correspondia a 7.224 habitantes (FERREIRA, 1958.p.352). Os dados do Censo de 1960 revelavam um crescimento 
da população urbana, dos 7.224 recenseados em 1950 passou-se para $12.373 \mathrm{em} 1960$ (OLIVEIRA, 2007, In, FONSECA, 1995, p. 141).

Os dados relativos ao Censo de 1950 indicavam que o ambiente urbano era constituído por 72 logradouros e 2887 prédios e congregava um centro comercial em desenvolvimento, contava na época com cerca de 130 estabelecimentos, com três agências bancárias, sete estabelecimentos de hospedagem e duas salas de cinema. Havia na cidade, ainda, a estação ferroviária da empresa Viação Férrea Federal Leste Brasileiro, que garantia a Jacobina a condição de entreposto comercial regional, em que se destacava a exportação de produtos como: "ouro, mamona, algodão beneficiado, fibra de sisal, queijos, coquilho de babaçu e coquilho de ouricuri” (FERREIRA, 1958.p.353).

Na década de 1950, a cidade era sede administrativa de órgãos estaduais e federais, que incluía uma residência da Comissão do Vale do São Francisco, agência dos Correios, Posto Regional de Trânsito, a sede de uma das regiões de atuação do fisco estadual e comarca de $3^{\text {a }}$ entrância do poder judiciário estadual. Além disso, possuía escolas de nível primário e, a partir de 1956, passou a contar o funcionamento do Ginásio Estadual Deocleciano Barbosa de Castro (FERREIRA, 1958.p.353-354).

\section{A "conquista da água encanada" na cidade de Jacobina (BA)}

A implantação do serviço de água encanada era uma questão estratégica para o projeto de vida urbana desejada para Jacobina naquele contexto. Por um lado, era um fator que pesava positivamente na construção da imagem de cidade "civilizada" e em "ritmo de progres- so". Por outro, a partir do conhecimento técnico da engenharia, implantava-se, no subsolo da cidade, uma rede de equipamentos invisíveis, mas de valor inestimável do ponto de vista médico-sanitário e de melhoramento do nível de saúde da população. A rede de distribuição de água, com a canalização para as residências, casas comerciais e chafarizes, passaria a transportar a água tratada por processos químicos de purificação medidas prescritas em nome da preservação da saúde da população citadina.

A questão do cuidado com a água consumida era alvo de preocupação por parte dos médicos do Distrito Sanitário ${ }^{2}$, sendo um dos itens abordados na campanha de educação sanitária desencadeada na cidade ${ }^{3}$. Num artigo publicado no Vanguarda, o médico sanitarista Evandro Oliveira Campos manifestava a seguinte inquietação:

\begin{abstract}
Ninguém, de mediana cultura, desconhece a influência que exercem as perfeitas instalações hidrotécnicas sôbre o decréscimo da mortalidade da população de uma cidade. As estatísticas têm demonstrado que a baixa da mortalidade é uma consequência dos cuidados de higienização dos abastecimentos hídricos. Longe, infelizmente, estamos de nos filiarmos ao grau de salubridade, segundo o conceito dos higienistas americanos, os quais estimam aquêle grau para a cidade, cuja mortalidade, por febre tifóide, não seja superior a 5 por 100.00 habitantes; nós apresentamos uma cifra de em tôrno de 13,5 por 100.000 habitantes (sic). (OLIVEIRA, 1956. p.4)
\end{abstract}

$\mathrm{O}$ assunto também passava pelo horizonte de preocupação do prefeito municipal Orlando Oliveira Pires, que, na mensagem de prestação de contas da gestão, encaminhada à Câmara Municipal no ano de 1957,

\footnotetext{
${ }^{1}$ A expressão "conquista da água" foi utilizada na produção historiográfica européia nas décadas de 1980 e 1990, sendo usada pelos autores Jean Pierre Goubert (1986) e Juan Manuel Matés-Barco (1999). O primeiro pesquisou a respeito do processo de universalização do serviço de água encanada na França, enfatizando a influência do saber dos engenheiros e dos médicos na construção dos equipamentos modernos de saneamento urbano. O segundo tratou de analisar os interesses entre o governo espanhol e as companhias privadas na comercialização do serviço de água encanada na Espanha no século XIX.

${ }^{2}$ O Distrito Sanitário era um órgão de saúde pública do estado da Bahia. O Distrito de Jacobina foi instalado em 1948. De acordo com o Código Sanitário do Estado (1925), os distritos deviam ser localizados nas regiões mais ricas e de maior densidade populacional e deviam desenvolver atividades como educação sanitária e política sanitária, combates de doenças na área rural, de epidemias, de patologias venéreas, de doenças como lepra e tuberculose; realizar cuidados com a maternidade e a saúde de crianças, além da inspeção de alimentos.

${ }^{3}$ A campanha de educação sanitária empreendida pelos médicos-sanitaristas constituía na prática de publicação de textos informativos e transcrição de trechos do Código Sanitário nas páginas do periódico Vanguarda, e na realização de eventos públicos, em que eram exibidos filmes e realizados palestras. Além de pronunciamentos através do serviço de alto-falantes da cidade.
} 
no tópico sobre o andamento da instalação do serviço de água encanada, destacou o processo científico de tratamento:

\section{[...] revestimentos da barragem, do las- tro do canal adutor bem como suas pare- des e ainda a construção dos 'filtros len- tos'. Estes em verdade irão proporcionar à população jacobinense um consumo de água cientificamente tratada. (PIRES, 1957.)}

Os editores do Vanguarda, igualmente, inquietavam-se com o tema. O texto intitulado A Pureza da Água Interessa a Todos, publicado no periódico, citava um panfleto difundido pelo Serviço de Saúde Pública dos Estados Unidos, que fazia referência à importância do cuidado com a pureza da água, nesses termos: "lembrou ao povo norte-americano que todos os cidadãos têm obrigação de zelar pela saúde de sua família e da comunidade, conhecendo a situação local da água e, se for possível, ajudando a melhorar esta situação " (VANGUARDA, 1957. p.4).

O jornal Vanguarda foi fundado em 13 de agosto de 1949. Tinha como proprietários e redatores Floriano Mota e Enéas Mota e funcionava na cidade de Feira de Santana. Contudo, em 1955, foi transferido para Jacobina, onde passou a circular. O jornal era registrado pela lei de imprensa, composto de quatro páginas, comercializado de modo avulso ou por assinatura e tinha uma abrangência de circulação regional, chegando às cidades circunvizinhas como Piritiba, Mundo Novo, Miguel Calmon, Campo Formoso e Feira de Santana. Nas suas edições, publicadas semanalmente (aos sábados), eram veiculados artigos dos editores, colunas assinadas por escritores locais, notícias da cidade, estaduais e nacionais. Além de publicidades de estabelecimentos comerciais de Jacobina e da região, ele publicava notas e editais da prefeitura de Jacobina e do Poder Judiciário.
Em notas e artigos, os editores e articulistas do Vanguarda produziram uma imagem positiva do prefeito. Nas publicações, divulgavam e faziam elogios pelas intervenções urbanas empreendidas pela gestão e elaboravam uma narrativa da história da cidade. Nas páginas do jornal, fora veiculada a imagem do prefeito como um homem dinâmico, capaz de impor uma nova racionalidade sobre a cidade e responsável por inserir Jacobina no caminho do "progresso" e elevá-la à condição de cidade "moderna" e "civilizada" (SILVA, 2015).

Comparando o discurso do médico sanitárista, do prefeito e do jornal, percebe-se em comum a preocupação com o tratamento da água consumida e o medo de doenças e epidemias transmissíveis através da água. A água consumida pela população citadina passava a se constituir num "problema", no qual, o saber médico e o científico deviam intervir. Assim, a cidade e o seu corpo social passavam a ser pensados e administrados a partir de preceitos e práticas médicos sanitaristas, cujo objetivo constituía o melhoramento das condições de saúde e a diminuição da taxa de mortalidade da população. ${ }^{4}$

Na década de 1950, estava em pauta no país a relação entre as boas condições sanitárias e a perspectiva de desenvolvimento nacional. As precárias condições de saúde da população brasileiras passaram a ser entendidas e tratadas como um problema no caminho do desenvolvimento nacional. Algumas das obras de urbanismo da gestão do prefeito Orlando Oliveira Pires (19551959) foram desenvolvidas com a participação do governo federal. Especificamente no contexto do governo do presidente Juscelino Kubitschek (1955-1960), que desenvolvia um projeto de desenvolvimento nacional, órgãos federais, como o Serviço Especial de Saúde Pública (SESP) e o Departamento Nacional de Obras Contra a Seca (DNOCS), em parceria com a prefeitura de Jacobina, desenvolveram a construção do serviço de água encanada e a autarquia federal Comissão do Vale

\footnotetext{
${ }^{4}$ De acordo com Michel Foucault, a partir do século XIX, mas, sobretudo, no século XX desenvolveu-se um novo mecanismo de poder, denominado de biopoder. Essa nova prática de poder para Foucault era exercida através de diversos dispositivos e distinguiu-se por governar elementos específicos do corpo social (doenças, mortalidade, natalidade, sexualidade, habitação, alimentação, condições sanitárias das cidades, expectativa de vida). Foucault definia como a entrada da vida na história, o corpo vivente tornou-se objeto de preocupação política: "a entrada dos fenômenos próprios à vida da espécie humana na ordem do saber e do poder - no campo das técnicas políticas". (FOUCAULT, 1988.p.154). Portanto, investir e administrar o corpo social, a vida humana enquanto espécie, no sentido biológico. No século XX viu-se a emergência e o desenvolvimento de ações e intervenções institucionais de governos no sentido de melhorar o nível de saúde e da expectativa de vida da população, como práticas sanitaristas nas cidades, combates de epidemias, políticas de vacinação da população. Intervenções que visavam ajustar as massas populacionais às necessidades do aparelho produtivo, na perspectiva do uso do corpo social para a sua melhor utilidade econômica (exploração da força de trabalho) e produção de corpos dóceis (docilidade política).
} 
do São Francisco (CVSF) trabalhou na ampliação do serviço de energia elétrica de Jacobina.

Mas como era o abastecimento de água na cidade antes desse melhoramento urbano? Pelas informações levantadas nas fontes pesquisadas (jornal e fotografia), Jacobina era abastecida por aguadeiros: profissionais que carregavam latas ou vasos de água na cabeça ou no lombo de animais, e vendiam nas ruas. Eram utilizados como fonte os rios (Rio do Ouro e ItapicuruMirim) que cortavam a cidade. Todavia, não podemos descartar outras modalidades de provimento de água para os afazeres cotidianos que, porventura, existiam, como por exemplo, o armazenamento de água da chuva.

O consumo da água na cidade movimentava seus fornecedores, os aguadeiros. Tal atividade, presente na paisagem urbana e no cotidiano doméstico, foi citada nos escritos memorialísticos de Amado Honorato de Oliveira. Numa série de pequenos textos classificados como contos, escritos em 1999, Honorato de Oliveira, narrava suas memórias de juventude, em que descrevia personagens e eventos pitorescos das ruas de Jacobina. Num dos escritos, mencionava a atividade de aguadeiro sendo exercida e indicava detalhes do ofício urbano:

Jacobina ainda não tinha recebido o beneficio da água encanada. O Rio do Ouro era o seu principal manancial e os aguadeiros se tornaram famosos servidores que não paravam durante todo o dia transportando latas d'agua para o abastecimento local. Ali, na Ponte do Convento, do lado da casa de Dona Nena, havia uma descida com degraus onde as vasilhas eram cheias.

Os aguadeiros que podiam, compravam jumentos para o carrego dos "carotes", usados no transporte do precioso líquido para os locais mais distantes da cidade (OLIVEIRA, 1999, p.19).

De tal modo, citava os nomes de "Cícero, o Rezador" e Maria Benvinda, como conhecidos aguadeiros. Acerca da última, escreveu:

Ela ganhava a vida carregando latas d'agua do Rio do Ouro para a sua enorme freguesia. A sua ida-e-vinda para servir talvez fosse maior que todos os aguadeiros juntos. Começava o trabalho no romper do dia e alcançava o cair da noite (OLIVEIRA, 1999, p.17).

Como se pôde perceber nas descrições de Amado Honorato de Oliveira, os aguadeiros eram sujeitos presentes na paisagem urbana, desempenhavam um ofício de suma importância para a cidade, coletavam e transportavam a água, abastecendo as residências e possibilitando o funcionamento delas. Nas moradias, a água podia ser armazenada em potes, vasos, cisternas, baldes, bacias e moringas, e utilizada nos diversos afazeres domésticos, como beber, cozinhar, lavar, banhar.

$\mathrm{Na}$ fotografia abaixo, registrada pelas lentes do fotógrafo Osmar Micucci, em 1956, identifica-se a presença de um vendedor de água de passagem pelo largo da Igreja da Conceição, em direção à Rua São Salvador.

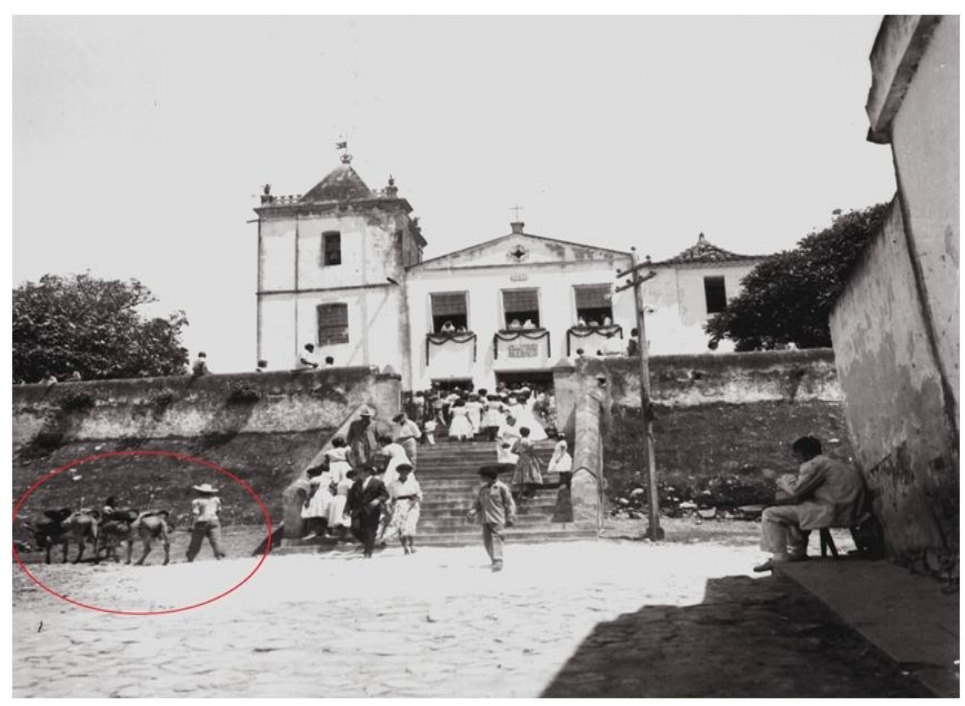

Imagem 1 - Igreja da Conceição - 1956.

Fonte: Fotografia de Osmar Micucci. Acervo: NECC/UNEB - CAMPUS IV.

$\mathrm{Na}$ composição da imagem fotográfica, diferentemente da criação de um pintor ou artista plástico, que tem o domínio técnico da elaboração da sua produção e seu resultado final, o fotógrafo não tem esse domínio completo da sua criação nem do seu resultado. O fotógrafo, por sua vez, utiliza-se de um aparelho (meio técnico) e a sua condição é limitada a explorar as possibilidades técnicas desse meio (FLUSSER, 1985). De tal modo, entende-se o porquê na fotografia, por vezes, existe alguma coisa na sua composição que escapa ou transborda na cena capturada pela objetiva, no instante do clique.

O foco da fotografia (apresentada na imagem 1) centra-se na Igreja e no movimento de pessoas a sua 
frente, a entrar e a sair do templo católico, contudo, na borda da imagem, verifica-se a figura de um aguadeiro no exercício do seu ofício, de passagem pelo lado esquerdo do largo da Igreja da Conceição, indo em direção à rua seguinte; fazia o percurso para o abastecimento de mais uma moradia. Como apontou a estudiosa da fotografia Susan Sontag, a imagem fotográfica pode ser manipulável, todavia, a fotografia mostra aquilo que existiu, apresenta um testemunho. "Uma foto equivale a uma prova incontestável de que determinada coisa aconteceu. A foto pode distorcer, mas sempre existe o pressuposto de que algo existe, ou existiu, e era semelhante ao que está na imagem" (SONTAG, 2004.p.16).

Giorgio Agamben, no texto O Dia do Juízo, expõe seu pensamento sobre o caráter da fotografia e apresenta o conceito de exigência:

Prezo especialmente o conceito de exigência, que não dever ser confundido com uma necessidade factual. Mesmo que a pessoa fotografada fosse hoje completamente esquecida, mesmo que seu nome fosse apagado para sempre por isso - aquela pessoa, aquele rosto exigem o seu nome, exige que não sejam esquecidos (AGAMBEN, 2007.p.29).

Para Agamben, a vida desse sujeito estaria condenada ao esquecimento, mas o gesto, o corpo na fotografia exigem que seja lembrado. Não sabemos seu nome, nem história de vida, aparece como um anônimo. Talvez o único momento de aparição desse indivíduo foi nessa fotografia, enquanto trabalhador urbano. Sua vida assim fora posta, marcada, no gesto cotidiano do labor nas ruas, conduzindo o jegue com o carregamento de água.

O uso das águas dos rios que cortavam a cidade era motivo de conflitos entre a administração municipal e os moradores que as utilizavam para lavagem de utensílios domésticos, de roupas e banhos. As lavagens de roupas eram representativas das tensões entre as medidas de normatização do espaço e as práticas cotidianas da população. Apesar de interditadas pelas posturas municipais na maior parte do leito dos rios, as lavadeiras, cotidianamente, expandiam os limites demarcados. Eram assim alvo de reclamações dos editores do jornal Vanguarda por usarem o espaço além do permitido. Como podemos ler neste texto publicado na primeira página do periódico Vanguarda:

\section{Estão Lavando Roupa nos Locais Proibidos Pelas Posturas Municipais!}

\begin{abstract}
Pessoas irresponsáveis e sem princípios estão lavando roupa no Rio do Ouro, acima dos locais em que a população jacobinense apanha água para beber e para outros fins domésticos.
\end{abstract}

Como é sabido, só é permitido a lavagem de roupa na confluência do Rio do Ouro com o Itapicuru-Mirim, fora dai é expressamente proibido pelas posturas municipais.

É necessário que os prepostos da Prefeitura redobrem a sua vigilância no Rio do Ouro a fim de evitar que indivíduos inescrupulosos continuem a lavar roupa nos lugares proibidos (VANGUARDA, 1959, p.1).

Contudo, também os aguadeiros eram alvo de críticas por parte dos jornalistas:

\section{Com Vistas aos Fiscais do Município}

\begin{abstract}
Solicitamos uma providência dos srs. Fiscais do Município contra o abuso de os (sic) aguadeiros deixarem os seus animais carregados, soltos pelas ruas a atropelarem as crianças e a impedir o livre trânsito de veículos nas vias públicas desta cidade; como ocorreu em dia desta semana com uma criança que recebeu brutal pancada do ancorote, na cabeça, que quase lhe fratura o crânio! (VANGUARDA, 1955, p.1).
\end{abstract}

Nas duas situações citadas, os jornalistas invocavam as prescrições das posturas municipais, manifestando-se em defesa da normatização do uso das ruas e das margens dos rios. De tal modo, imaginavam e desejavam uma cidade ordenada, com a disposição dos corpos circunscrita aos espaços delimitados pelo modelo da legislação urbana. No caso das lavadeiras, o transbordamento de suas práticas pelas margens dos rios assinalava uma maneira de consumir o espaço à 
revelia da concepção funcionalista e disciplinar. Nesse movimento, a cada dia conquistavam o espaço e estendiam os limites de lavagem de roupa definido pelas posturas.

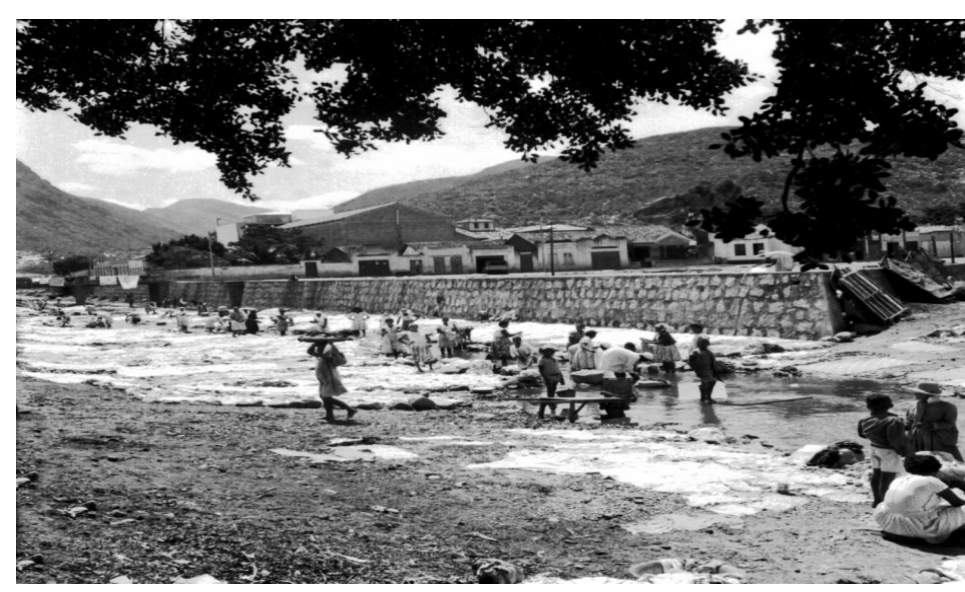

Imagem 2- Lavadeiras no Rio do Ouro - 1958.

Fonte: Fotografia de Osmar Micucci. Acervo: NECC/UNEB - CAMPUS IV.

Levando em consideração que a cidade não dispunha de serviço de água encanada e a população urbana crescia, seria possível que, no espaço delimitado, todas lavassem roupas? Era bem provável que não. A ampliação dos espaços demarcados pelas posturas por partes das lavadeiras, que incomodavam os jornalistas, era uma condição quase que indispensável para o desenvolvimento de afazeres (ex: lavagem de roupa, utensílios domésticos) no leito dos rios, nos dias de maior demanda. As lavadeiras, classificadas de forma depreciativa no texto do jornal como "irresponsáveis, sem princípios e inescrupulosas" (VANGUARDA, 1959, p.1), serviamse das águas para lavagem tanto de suas próprias vestes e utensílios, como de terceiros. O que se infere desses reclames era que as lavadeiras de roupa enfrentavam embates cotidianos em torno do uso das águas dos rios.

No episódio dos carregadores de água, a questão envolvia a presença dos animais no espaço urbano. Como de praxe, os editores clamavam a atuação da prefeitura no sentido de normatizar as atividades. As posturas municipais ordenavam que os animais devessem transitar pela cidade presos a cabresto e guiados pelo condutor, sob pena de multa aos proprietários que desrespeitassem. No texto, os jornalistas acionavam como argumento para a conservação da ordem da cidade, um apelo sensível: o cuidado com as crianças. Aliás, a preocupação com as crianças era um assunto que aparecia em voga nas páginas do Vanguarda. Uma série de notas em pequenas colunas no jornal, chamadas de "Conselho Útil", orientavam os leitores no sentido de se manter um cuidado especial com a saúde e a preservação dos direitos das crianças. ${ }^{5}$

No enunciado, era apresentada ainda a ideia de um livre fluxo do trânsito urbano, que estaria sendo obstruído pela presença dos animais. $\mathrm{O}$ livre movimento das ruas era um aspecto essencial para uma cidade que ambicionasse ser moderna. Para os editores do Vanguarda, que postavam-se como vigilantes atentos em defesa da ordem e do uso disciplinado dos espaços urbanos, essa devia ser a configuração assumida nas ruas de Jacobina. A propósito, essa era uma noção recorrente nos enunciados jornalísticos, presente nas posturas municipais e nas intervenções do gestor municipal. Assim, imaginavam e procuravam materializar um ambiente urbano fluido e a cidade cumprindo a função de deslocamento e mobilidade.

Contudo, não havia ainda um discurso no jornal no sentido de eliminar essas atividades, o que se buscava era tentar disciplinar, na utopia de fazer funcionar como prescreviam as normas. As atividades de aguadeiros e lavadeiras faziam parte de uma economia urbana e da paisagem cotidiana das ruas. Os primeiros, trabalhando no imprescindível serviço de abastecimento da cidade. As lavadeiras, por sua vez, tinham na lavagem de roupa uma fonte de renda.

Essas práticas seriam gradualmente abandonadas com a construção do serviço de canalização de águas para as residências ou de chafarizes. Desse modo, as obras caminhavam na transformação de antigos costumes e hábitos presentes na paisagem urbana. A introdução da água encanada seguia da prescrição de outro estilo de vida na cidade, configurado pela privatização do consumo da água

\footnotetext{
${ }^{5}$ Ver a coluna Conselho Útil nas edições: Vanguarda, 09/02/1957. №381.p.4; Vanguarda, 30/03/1957. No 387.p.4; Vanguarda, 06/04/1957.Nº.388. p.4. Vanguarda, 13/04/1957. N.389.p.2; Vanguarda, 20/04/1957. ํ3ㅇ.p.4; Vanguarda, 29/03/1958. N.437.p.3; Vanguarda, 21/09/1958. N²62.p.3. Direitos da Criança Brasileira - Vanguarda, 19/10/1958. N467.p.3.
} 
(tratada através de processos científicos de purificação ${ }^{6}$ ) e da eliminação de animais transportando o elemento hídrico pelas ruas. $\mathrm{O}$ processo de modernização da cidade aos poucos ia colocando de lado as antigas profissões de aguadeiro e de lavadeira: a primeira sendo excluída da paisagem urbana e a segunda sofrendo um deslocamento.

Em Jacobina, a implantação da água encanada começou a partir de 1955, com o Serviço Especial de Saúde Pública (SESP), órgão federal de natureza sanitária. Na página inicial do jornal Vanguarda, era anunciada a chegada dos materiais à cidade:

\section{Está chegando material para o serviço de A'gua (sic) Encanada}

Começou a chegar aqui o material destinado à instalação do serviço de água encanada desta cidade.

Já se encontram nos armazéns da Prefeitura Municipal cerca de 20 toneladas de tubos de várias dimensões, remetidos do Rio de Janeiro, pelo Serviço Especial de Saúde Pública (SESP), a quem está afeta (sic) a instalação de água encanada desta cidade.

O início dos trabalhos da Engenharia Sanitária está previsto para dentro de breves meses, provavelmente, antes do fim do ano em curso.

É esta, sem dúvida, uma notícia alviçareira para todos nós que aqui residimos. (VANGUARDA, 1955. p.1)

O SESP já tinha feito um estudo prévio para a realização dessa obra na cidade, como aponta um ofício enviado pelo prefeito ao superintendente da instituição, em que solicitava cópias do projeto (JACOBINA, 1955, p. 102). O referido órgão sanitário foi criado em 1942, no contexto da Segunda Guerra Mundial, numa parceria do presidente Getúlio Vargas com o governo norteamericano, e planejado com o propósito de desenvolver ações em regiões de exploração de materiais considerados estratégicos no contexto da guerra, como minérios e borracha.

No entanto, no contexto do Estado Novo varguista, o órgão desempenhou também uma atuação importante, auxiliando na expansão das ações do Estado brasileiro em regiões interioranas ausentes de políticas governamentais de saúde e saneamento. Com o fim do governo Vargas (1945) e da Segunda Guerra Mundial, houve um acordo para a continuidade do funcionamento do órgão. Diante da tensão política instalada entre o capitalismo estadunidense e o socialismo soviético, o SESP passou a servir no programa norte-americano de combate ao comunismo e a atender a interesses comerciais com a venda de produtos farmacêuticos e da indústria de saneamento. Porém, a continuidade das atividades era reivindicada também por representantes do governo brasileiro, e as ações do SESP foram mantidas no país (CAMPOS, 2005. p. 37-61).

Nos anos posteriores à Segunda Guerra Mundial, elaborou-se a associação entre política sanitária e o projeto de desenvolvimento nacional. As péssimas condições de saneamento e o baixo índice de saúde da população eram vistos como fatores que impediam o pretendido desenvolvimento do país. A partir de 1946, a agência bilateral passou a ser beneficiada com recursos federais para investimentos em regiões do país consideradas como subdesenvolvidas. Em 1949, foi assinado um contrato com estados da região Nordeste, a fim de organizar os serviços de saúde pública em áreas consideradas de importância econômica. O SESP cumpriu um papel significativo no país, na área de saúde pública e saneamento, principalmente nos anos da década de 1950. O governo do presidente Juscelino Kubitscheck (1956-1961) utilizou-se da agência para a prestação de serviços nas regiões consideradas como alvo do projeto nacional desenvolvimentista em curso na década de 1950 (CAMPOS, 2005. 37-61).

Além de ser um melhoramento estratégico no cuidado com a saúde da população, defendida pelos médicos e jornalistas, a água encanada era mais um

\footnotetext{
${ }^{6}$ Através das fotografias do jacobinense Osmar Micucci sobre as obras de construção do serviço de água encanada na cidade, foi possível identificar a construção de dois ambientes de armazenamento da água, sendo um da estação de tratamento, do qual o método utilizado não foi possível saber, e outro para cloração da água. Ambos foram construídos pelo Serviço Especial de Saúde Pública (SESP).
} 
equipamento urbano que, no imaginário dos jornalistas e dos gestores municipais, elevava Jacobina à condição de cidade "moderna", "civilizada" e "progressista". Dada a importância da obra para a cidade, pelos aspectos considerados acima, o prefeito demonstrou-se empenhado no andamento do empreendimento, como aponta esse ofício:

Oficio n.92 em 55

\section{Senhor Superintendente}

Pelo presente dirijo-me a V.S.a, no sentido de levar ao vosso conhecimento que a Prefeitura Municipal de Jacobina, está enviando todos os esforços a fim de dotar esta cidade do serviço de água encanada.

Assim sendo solicito de V.Sa. informes concretos que digna respeito:

a) Quais os meios que possam facultar a esta Prefeitura à realização da obra?

b) Qual a verba destinada ao Serviço Especial de Saúde Pública no presente exercício para o referido serviço? Informações outras que a critério vosso possam esclarecer o assunto serão de bom grado recebidas por esta Prefeitura, que pelo seu Prefeito confessar-se-a antecipadamente agradecido, subscrevendo-se com alta estima e elevada honra.

Cordialmente

(As.) Dr. Orlando Oliveira Pires

Prefeito

Ilmo Sr.

Dr. Aristóbulo Codevilla Rocha

DD. Diretor Superintendente da Comissão do Vale do São Francisco

Rio de Janeiro - Distrito Federal. (PIRES, 1955.p. 102-103).

Considerando que se tratava de um importante melhoramento ambicionado para a cidade, num primeiro momento, o gestor municipal solicitou ainda a autorização da Câmara Municipal para contrair um empréstimo bancário em nome da Prefeitura, (VANGUARDA, 1955. p.1) para contribuir com a instalação do serviço da água encanada. Em sessão da Câmara realizada em 12 de maio de 1955, foi colocada em pauta a discussão e votação do projeto de implantação do serviço. Ocasião na qual o prefeito encontrou votos contrários dos vereadores da oposição. Alegavam os opositores que só votariam a favor caso o dirigente municipal apresentasse o orçamento do serviço a ser construído, intimando, de certo modo, o prefeito para esclarecer a questão. $\mathrm{Na}$ ata da citada sessão, consta que, ao ser indagado pelo vereador da oposição Ubaldino Mesquista Passos, o prefeito contrapôs que:

\begin{abstract}
$o$ orçamento atingia a uns CR\$ 8.500.000,00 (oito milhões e quinhentos mil cruzeiros) mais ou menos e acrescentou que já está recebendo material destinado ao Serviço, proveniente de providências do então Prefeito Dr. João Batista Freitas de Matos.(CÂMARA DE VEREADORES, 1955, p.182).
\end{abstract}

A obra de modernização urbana resultava ainda num meio de promoção e projeção política para as lideranças locais, que, através dos órgãos federais, buscavam angariar recursos financeiros para o andamento das obras. O semanário Vanguarda, que colaborava com o enaltecimento desses personagens (prefeito, deputados), trazia, nas suas edições, textos informativos das movimentações políticas em torno do andamento das obras. Como podemos ler nessa nota:

\section{Está sendo encaminhado o pro- blema de água encanada}

O importante problema de água encanada para esta cidade vai, pouco a pouco, sendo equacionada, graças às providências tomadas pelo representante deste Município, dep. Francisco Rocha Pires, juntamente com o deputado federal $d r$. Manuel Novais, incansável batalhador em prol das cousas da nossa terra.

Além da verba de seiscentos mil cruzeiros já aplicada na compra da tubulação que se encontra nos depósitos da Prefeitura local, o dep. Novais acaba de telegrafar ao dep. Rocha Pires, comunicando-lhe ter conseguido da Comissão do Vale do S. Francisco, uma dotação de um milhão de cruzeiros para a instalação do serviço de água encanada nesta cidade.

Por outro lado, o prefeito municipal, $d r$. Orlando Oliveira Pires, tem tomado vá- 
rias providências junto à Comissão do Vale do S. Francisco e ao Serviço Público, no mesmo sentido.

É sobremodo agradável para todos nós saber que o aludido problema está sendo encaminhado, com dedicação e interesse, para breve solução. (VANGUARDA, 1955. p.1).

A instalação do serviço envolvia a construção de um reservatório e da rede adutora. De acordo com editores do Vanguarda, o designado "operoso prefeito do Município", Orlando Pires, tinha viajado ao Rio de Janeiro, então capital do país. Nessa viagem, havia conseguido, junto com a Comissão do Vale do São Francis$\mathrm{co}^{7}$ (CVSF) e com o Serviço Especial de Saúde Pública, o valor de "dois milhões de cruzeiros" para compra do material para a edificação da adutora. No ano seguinte (1957), era noticiado que o material começava a chegar à cidade. (VANGUARDA, 1957.p.1).

A construção da obra foi feita pelo $4^{\circ}$ Distrito do Departamento Nacional de Obras Contra Seca - DNOCS ${ }^{8}$, cujo responsável era o engenheiro Desildo Meneses. O aludido órgão ficou com a parte de construção da rede distribuidora (canalizações nas ruas), da adutora e do reservatório (Imagem 3 - abaixo). Já a parte de aumento da barragem ${ }^{9}$ e a edificação da estação de tratamento da água foram entregues à responsabilidade do Serviço Especial de Saúde Pública (Imagem 4 - abaixo). O saber médico e da engenheira se entrecruzavam em prol do melhoramento da saúde pública na cidade.

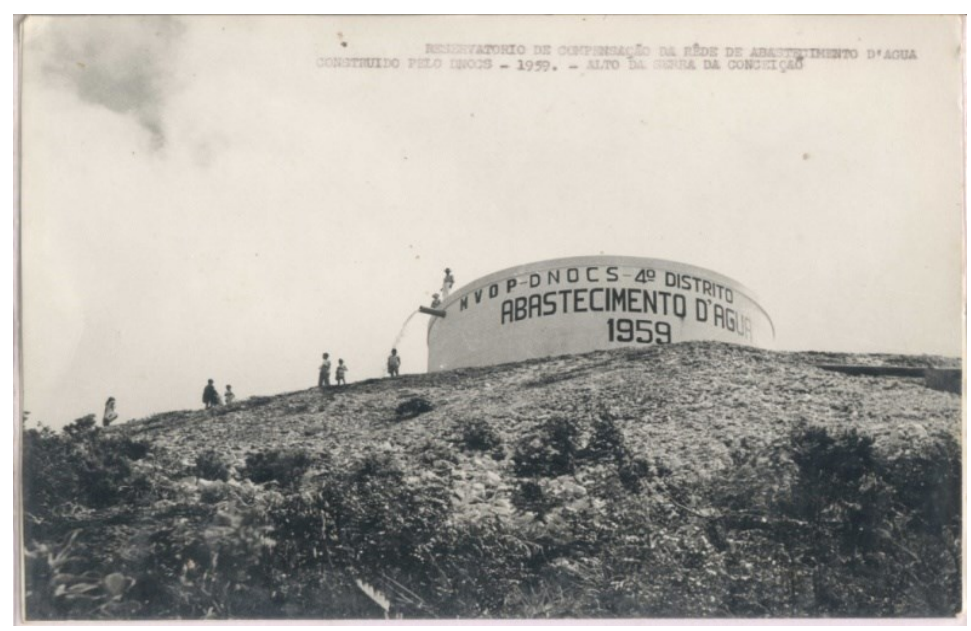

Imagem 3 - Reservatório construído pelo DNOCS no alto da Serra da Conceição - 1959 .

Fonte: Fotografia de Osmar Micucci. (Acervo: NEO/UNEB- CAMPUS IV).

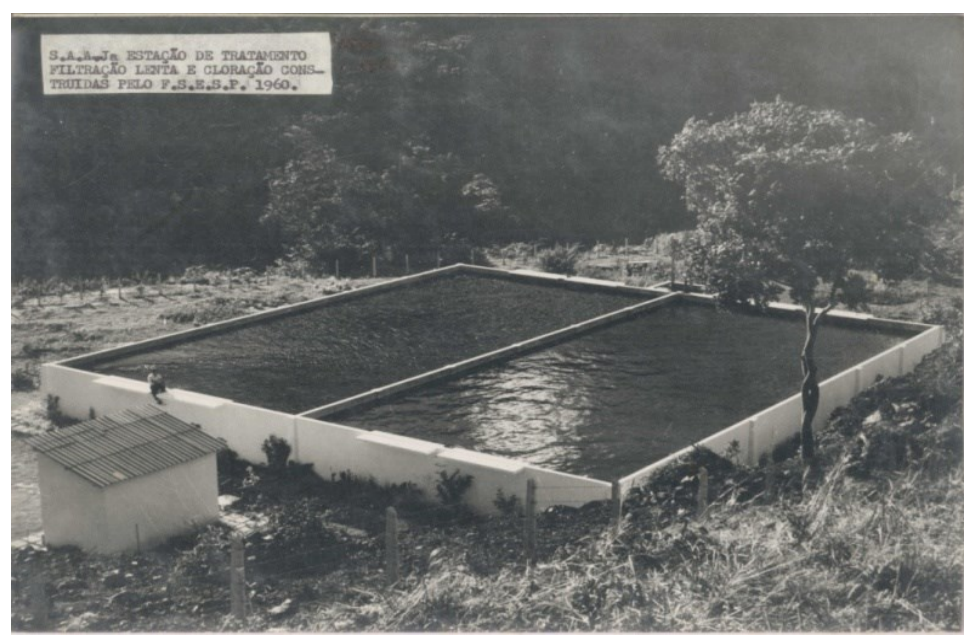

Imagem 4 - Estação de tratamento do sistema de água encanada - 1960.

Fonte: Fotografia de Osmar Micucci. (Acervo: NEO/UNEB- CAMPUS IV).

Na primeira página do Vanguarda da edição de número 432, em 1958, os editores analisavam o andamento dos trabalhos:

\footnotetext{
${ }^{7}$ A Comissão do Vale do São Francisco - foi constituída em 1948. Seu objetivo era produzir e executar o Plano de Aproveitamento das Possibilidades Econômicas do Rio São Francisco. Entre as atividades previstas para o plano (1950), incluía-se uma diversidade de funções e construção de obras, como melhoramento nos sistemas de transportes e comunicações; edificação de usinas hidrelétricas, estações centrais e redes de transmissão; obras de saneamento no campo e nas cidades, serviços de saúde pública, projetos de irrigação e de estimulo à agricultura; levantamento de informações sobre recursos minerais, ações de reflorestamento e desenvolvimento da imigração e colonização.

${ }^{8} \mathrm{O}$ citado órgão federal foi instituído no contexto da Primeira República pelo presidente Nilo Peçanha através do Decreto No 7.619 , de 21 de outubro de 1909, quando recebeu o nome de Inspetoria de Obras contra as Secas - IOCS. Em 1919 passou a chamar-se de Inspetoria Federal de Obras Contra as Secas - IFOCS. A partir de 1945, o órgão recebeu uma nova nomenclatura, a qual permanece até hoje, a saber, Departamento Nacional de Obras Contra as Secas (DNOCS). O objetivo da instituição era organizar ações de combate às secas na região Nordeste. Contudo, para além das medidas de intervenção com relação às secas como a construção de açudes, o órgão também foi responsável por obras de infraestrutura na região, atuando na abertura de estradas, edificação de hospitais, campos de pouso, pontes, ferrovias; construção de usinas hidrelétricas, de redes transmissão elétrica e telegráfica.

${ }^{9} \mathrm{~A}$ citada barragem represava as águas do Rio do Ouro, foi construída onde era localizada a antiga usina hidrelétrica, no lugar hoje conhecido como Parque da Macaqueira
} 
A Instalação do Serviço de Água Encanada Nesta Cidade

Os trabalhos de instalação de água desta cidade encontram-se bastante adiantados. Em quase todas as ruas do perímetro urbano já foi assentada a respectiva tubulação.

Espera-se que, terminados esses trabalhos, seja imediatamente assentada a adutora e construído o reservatório para a distribuição do precioso líquido à população local. (VANGUARDA, 1958.p.1).

Em edição ulterior, era divulgado no jornal que o Serviço Especial de Saúde Pública havia começado a edificação da estação de tratamento de água. De acordo com o texto, a estação era composta de um reservatório da água bruta, decantador e filtros (VANGUARDA, 1958. p.1). No entanto, ocorreram dificuldades para a conclusão das obras; a construção da estação de tratamento foi paralisada em 1958 e retomada somente alguns meses depois, já no ano seguinte.

A construção do sistema de água encanada era mais um mecanismo da estratégia de gestão da cidade. Importante melhoramento que servia tanto no sentido de diminuir o índice de mortalidade da população, resultando no aumento da sua expectativa de vida, como projetava Jacobina como um centro urbano adiantado, em sintonia com o "progresso" e a "civilização". Iniciada a construção na gestão de Orlando Oliveira Pires, foi executada por órgãos federais em parceria com a Prefeitura, sendo finalizada e inaugurada na gestão do médico Florivaldo Barberino (1959-1963). Na administração desse último, foi elaborado o projeto de regulamentação e constituição de uma empresa municipal de economia mista para administrar o serviço, denominada Sociedade Anônima de Água e Esgoto (SAAE). ${ }^{10}$

A entrega do serviço de abastecimento de água à Prefeitura de Jacobina foi feita em 21 de novembro de 1960, com a presença do engenheiro Desildo Meneses do DNOCS e do diretor do SESP, Domingos Lavigne de Lemos. Também foram construídos pelo DNOCS, o SESP e a Prefeitura, chafarizes públicos em alguns logradouros afastados das ruas centrais da urbe. Foram edificados pelo DNOCS dois chafarizes: um primeiro na Praça Dr. J. J. Seabra (hoje Praça da Bíblia) e um segundo no Alto da Missão. Na Praça da Concórdia, no bairro da Serrinha, o SESP construiu mais um. Em 1963, a prefeitura inaugurava outro na Praça Miguel Calmon. Nas ruas centrais da cidade, não há registro de construção de chafarizes, certamente as edificações situadas naquele espaço passaram a ter o conforto urbano da água canalizada - penetrando nas paredes dos cômodos e destilados nas torneiras. Dessa forma, enquanto os moradores e proprietários das ruas centrais da cidade passavam a possuir a água canalizada para suas residências e estabelecimentos comerciais, os moradores dos bairros afastados ficavam a disputar a água nos chafarizes públicos. O conforto urbano da canalização para as residências não vinha para todos, os moradores dos bairros afastados do centro da urbe restava o recurso das latas de água na cabeça.

De um modo geral, a modernização da cidade empreendida naquele contexto foi feita de maneira seletiva e desigual, concentradora de serviços urbanos num território. Nas ruas centrais da cidade, produziu-se um espaço estruturado com serviços e equipamentos urbanísticos de conforto; em contraposição, outros espaços ficavam destituídos dessa rede de estruturação urbana. Assim, a rede de água encanada para as residências era mais um elemento que valorava os imóveis, estimando o preço deles; como também estabelecia distinções dentro do território urbano, demarcando diferenças sociais.

\section{Considerações finais}

A modernização do processo de captação e distribuição de água na cidade impôs transformações nas práticas sociais e na paisagem urbana naquele contexto. Provocou modificações em ofícios urbanos, a exemplo do aguadeiro e da lavadeira de roupa, o

\footnotetext{
${ }^{10}$ A proposta de criação foi feita na gestão de Florivaldo Barberino, no entanto, a lei autorizando o município a criar a referida empresa só foi promulgada na gestão posterior, de Ângelo Brandão.
} 
primeiro condenado ao desaparecimento e a segunda foi deslocada possivelmente das margens dos rios. Por outro lado, a modernização também passava a condicionar o que era visto ou não nas ruas. Aos poucos se configurava uma nova imagem das ruas, com o desaparecimento dos aguadeiros e o estabelecimento de um novo sistema de distribuição de água. Assim a água era deslocada da sua movimentação visível, carregada no lombo de animais sobre vasos, com aguadeiros a transportar pelas vias urbanas e a entregar nas casas, passava a ser transportada por meios de redes invisíveis, de canos e torneiras.

Para os médicos, prefeito e imprensa local, a instalação do serviço de água encanada devia atender aàdemanda do melhoramento das condições de saúde da população citadina; cruzando esses diferentes olhares sobre a questão, entende-se que era importante naquele momento resolver a equação, diminuir $o$ número de mortes decorrentes de agentes nocivos transmitidos pela água e aumentar a expectativa de vida da população. Assim, a instalação do serviço de água encanada na cidade deve ser compreendida dentro de um contexto histórico (nacional e internacional): questões de natureza política e econômica do período também contribuíram para a conquista do sistema de água encanada para parte da cidade.

Naquele momento, estava em pauta, no país, o pensamento desenvolvimentista, sendo um dos elementos necessários para o desenvolvimento nacional o melhoramento das condições sanitárias e de saúde pública da sociedade brasileira. Através do SESP, instituição federal que tinha como objeto de atuação as questões sanitárias e de saúde pública, foram investidos recursos federais na construção do sistema de água encanada e de chafarizes públicos em Jacobina. Por outro lado, os personagens locais como prefeito, jornalistas e políticos viam a conquista do equipamento urbano de maneira auspiciosa; o jornal Vanguarda, por sua vez, informava e exaltava para seus leitores as ações e negociações articuladas pelos representantes políticos locais em prol da execução das obras em Jacobina. A implantação do serviço de água encanada era mais um elemento de modernização e saneamento, que no imaginário urbano em voga no contexto elevava a cidade a ser vista como "civilizada", "moderna", em que chegava o "progresso".

Ademais, o serviço de água encanada foi distribuído de maneira desigual no espaço urbano: de um lado, as ruas centrais com a canalização para as residências, por outro, ficaram as ruas dos bairros às margens do perímetro central servidas de chafarizes públicos. Porém, não foi apenas tal dispositivo, outros equipamentos e serviços de conforto urbano como o sistema de esgoto, o serviço de energia elétrica, a pavimentação das ruas assim também foram construídos. Contudo, pode-se considerar que a presença dos chafarizes para aquela população servida com tal mecanismo podia ser vista como um ganho, a água mais perto de casa tinha suas vantagens. Os chafarizes instauravam-se uma nova maneira de consumir a água na cidade, como também funcionavam enquanto um ambiente de sociabilidade, que, por sua vez, impunham novas dinâmicas de relações sociais. 


\section{Referências}

ARANHA, Gervácio Batista. Seduções do moderno na Parahyba do Norte: trem de ferro, luz elétrica e outras conquistas materiais e simbólicas (1880-1925). In: A Paraíba no Império e na República: estudos de história social e cultural. AGRA DO Ó, Alarcon. (Org:). 2. ed. João Pessoa. Editora Idéia, 2005. p.79-132.

AGAMBEN, Giorgio.O dia do juízo. In: Profanações. Tradução: Selvino José Assmann. São Paulo. Boitempo, 2007.p.27-30.

BEGUIN, François. As maquinarias inglesas do conforto. Tradução: Jorge Hagime Oseki. In: Espaço e Debate $n^{\circ}$ 34. Revista de Estudos Regionais e Urbanos. São Paulo. 1991.p.39-54.

CAMPOS, André Luiz Vieira de. O Serviço Especial de Saúde Pública: Políticas Internacionais e Respostas Locais. História em Revista, Pelotas, v. 11, dezembro/2005.p. 37-61.

DE PAULA, Dilma Andrade. A Comissão do Vale do São Francisco: planejamento e política pública nas décadas de 1940-1950. Disponível em: <http://www.historia.uff.br/estadoepoder/files/UFS2010Dilma.pdf>

FERREIRA, Jurandyr Pires. Jacobina. Municípios do Estado da Bahia. In: Enciclopédia dos Municípios Brasileiros. Volume XX. IBGE. Rio de Janeiro, 1958. p.352. Disponível em: <http://biblioteca.ibge.gov.br/ visualizacao/livros/liv27295_20.pdf>. Acesso em: 25 mar. 2014.

FOUCAULT, Michel. História da sexualidade I. A vontade de saber. Tradução: Maria Thereza da Costa Albuquerque e J.A. Guilhon Albuquerque. Rio de Janeiro. Edições Graal, 1988.

GOUBERT, Jean Pierre. La conquête de l'eau. L'avénement de la santé à l'âge industriel. Paris. R. Lanffont,1986.

LUCA, Tania Regina de. História dos, nos e por meios dos periódicos. In: Fontes Históricas. Carla Bassanezi Pinsky. (Org:). 3.ed. São Paulo. Contexto, 2011.p.111-153.

MATÉS-BARCO, Juan Manuel. La Conquista del agua. Historia económica del abastecimiento urbano. Jáen. Universidad de Jáen, 1999.

MORAES, Kleiton de. Inspetoria Federal de Obras Contra as Secas (Ifocs). Disponível em: <http://cpdoc.fgv.br/ sites/default/files/verbetes/primeirarepublica/INSPETORIA\%20FEDERAL\%20DE\%20OBRAS\%20CONTRA\% 20AS\%20SECAS.pdf>

SANT'ANNA, Denise Bernusi de. Cidades das águas. Usos de rios, córregos, bicas e chafarizes em São Paulo (1822-1901). São Paulo: Editora SENAC, 2007.

SENNET, Richard. A Carne e a pedra: O corpo e a cidade na civilização ocidental. Tradução: Marcos Aarão Reis. Rio de Janeiro. BestBolso, 2008.p.261-288.

SIMMEL, Georg. A metrópole e a vida mental. In: O fenômeno urbano. Otávio Guilherme Velho. (Org:) Tradução: Sérgio Marques dos Reis. $4^{\mathrm{a}}$ ed. Rio de Janeiro. Zahar, 1979.p.11-25.

SILVA, Edson. Modernização, sanitarismo e cotidiano (Jacobina 1955-1959). Universidade Federal de Campina Grande, Campina Grande, 2015. (Dissertação de Mestrado).

SONTAG, Susan. Sobre fotografia. Tradução: Rubens Figueiredo. São Paulo. Companhia das Letras, 2004.

VIGARELLO, Georges. O Limpo e o Sujo. A Higiene do Corpo desde a Idade Média. Tradução: Isabel St. Aubyn. Lisboa. Editorial Fragmentos, 1985.

Submissão: 11/03/2017 Aceite: $21 / 01 / 2018$ 